\title{
The cue-depreciation effect on unprimed words
}

\author{
ANJALI THAPAR \\ Case Western Reserve University, Cleveland, Ohio
}

(Robert L. Greene, Sponsor)

\begin{abstract}
In a word-fragment-completion task, words cued all at once (e.g., O_T_OD_X) have an advantage over words cued incrementally (e.g., $\mathrm{O}_{-} \mathrm{C}_{--} \mathrm{X}, \mathrm{O}_{--} \mathrm{O}_{-} \mathrm{X}, \mathrm{O}_{-} \mathrm{OD}_{-} \mathrm{X}$, O_T_OD_X). The advantage of standard cues over incremental cues is referred to as the cuedepreciation effect. Typically, this effect has only been observed with previously primed target items. This study investigated whether the cue-depreciation effect can be found in unprimed items. In both experiments reported here, the cue-depreciation effect was found in words that were not previously primed.
\end{abstract}

The cue-depreciation effect was first reported by Peynircioglu and Watkins (1986), who showed that it is harder to complete a word fragment when the letters are disclosed gradually (e.g., $\mathrm{O}_{-}{ }_{-}{ }_{-} \mathrm{X}, \mathrm{O}_{-} \mathrm{O}_{-} \mathrm{X}$, $\left.O_{-}-O D_{-} X, O_{-} T_{-} O D_{-} X\right)$ than when they are shown all at once (e.g., $\left.O_{-} T_{-} O_{-} D_{-}\right)$. Although the effect is usually found only with primed words, there is some evidence that it may occur with unprimed words as well (Thapar \& Greene, 1992). The cue-depreciation effect appears to be the result of the strategies employed by the subjects. Thapar and Greene (1992, Experiment 1) found that subjects do poorly when exposed to a series of incremental cues because they become less likely to generate actively the possible solutions for the word fragments.

This study further explores the hypothesis that the cuedepreciation effect is the result of strategies. Experiment 1 manipulated the word-fragment task so that in the incremental condition, the first letter of the word was not revealed until the last fragment. In previous studies, the first letter was always included in the first fragment. In Experiment 2 , subjects were given a list of study words but were tested on a different set of words than those they were previously exposed to. These experiments explored various manipulations in an attempt to further induce the cue-depreciation effect in words that have not been previously primed.

\section{EXPERIMENT 1}

\section{Method}

Forty introductory psychology students participated to fulfill a course requirement. One to three subjects were tested at a time. A total of 122 eight-letter words were selected from a pool supplied by Gibson and

This research was supported by the National Institute of Child Health and Human Development Mental Retardation Research Training Grant 5-T32-HD07176-12. Correspondence should be addressed to A. Thapar, Department of Psychology, Case Western Reserve University, Cleveland, $\mathrm{OH} 44106$.
Watkins (1988). The only criterion was that the first letter of the word not be used to construct its unique two-letter fragment. Two of the words were randomly selected to serve as practice items. The remaining 120 words were assigned to four 30-word lists. For the study phase of the experiment, each of the four lists was typed on a separate sheet of paper in double-spaced columns in capital letters. For the testing phase of the experiment, the unique two-letter fragment cues designated by Gibson and Watkins were used. Additional letters were randomly added to the two-letter fragments to make the three- and four-letter fragment cues. The first letter of the word was always used to construct the five-letter fragment cue.

The cues for the word-fragment-completion test were laser printed on cards in 25-mm-high capital letters. In the incremental condition, the four fragments of each word (e.g., $\mathbf{O}_{-}$ $\left.O_{-} O_{-} X, O_{-} O_{-} O D_{-} X, O_{-} T \_O D_{-} X\right)$ appeared one under the other on the cue card. For the standard condition, only the fiveletter fragment of each word (e.g., $\left.O_{-} T_{-} O_{1} D_{-}\right)$appeared on the cue card. The answer sheets were designed so that for each word there were four lines, one under the other, constructed by eight slashes to represent the eight letters of the words.

The experimenter instructed the subjects in the study condition that a word-fragment-completion test would be given and that all the items on this test would come from the study list. The nonstudy groups were instructed on how to complete the word-fragment-completion test. After hearing detailed instructions, all subjects were presented with the two practice words. The subjects in the study condition were given a list of $\mathbf{3 0}$ words to read silently to themselves at a rate of one word per $2 \mathrm{sec}$, as timed by the experimenter. The experimenter used a stopwatch to keep time and indicated that the subject should move on to the next word on the list by saying "now." The subjects in the nonstudy condition were allotted a 1-min rest break between tests. After the study phase or the rest break, the subjects were given a word-fragment-completion test.

The word-fragment-completion test consisted of 30 words, 15 words appearing in the standard condition and 15 in the incremental condition. The ordering of the words was identical for both groups and was random with respect to fragment condition. Each subject was given $4 \mathrm{sec}$ to begin writing down a response for the words cued in the standard condition (i.e., with only a five-letter cue). For fragments cued in the incremental condition, the subject was given $4 \mathrm{sec}$ to write down a response for each fragment before the experimenter revealed the next fragment. The subject was instructed to write the word on the first line if it was retrieved with the two-letter fragment, on the second line if it was retrieved with the three-letter fragment, and so on. All mistakes were treated as no-answers. After each word-fragment-completion test was finished, the subjects in the study condition were given another list of study words and the subjects in the nonstudy condition were given a 1-min rest break. This continued until four tests were completed. Across 
subjects, words occurred equally often in the standard and incrementa format. Presentation condition (study or nonstudy) was a between-subject factor and test format (standard or incremental) was a within-subject factor.

\section{Results}

All analyses employed a significance level of .05 . In the study condition, the subjects completed $85.2 \%$ of the words cued in the standard condition and $79.3 \%$ of the words cued in the incremental condition. The subjects in the nonstudy conditions completed $69.2 \%$ of the words cued in the standard condition and $64.9 \%$ of the words cued in the incremental condition. An analysis of variance (ANOVA) established that the effect of presentation $\left[F(1,38)=46.77, M S_{\mathrm{e}}=35.41\right]$ and the effect of test format $\left[F(1,38)=31.72, M S_{\mathrm{e}}=5.87\right]$ were significant. The interaction between presentation and test format $\left[F(1,38)=0.69, M S_{e}=5.87\right]$ was not significant. The effect of test format was significant for both the study condition $\left[F(1,19)=27.87, M S_{\mathrm{e}}=4.40\right]$ and the nonstudy condition $\left[F(1,19)=9.21, M S_{e}=7.34\right]$ when they were analyzed separately. When the first letter of a word was not revealed until the end, the subjects exposed to the incremental fragments were less likely to generate solutions.

\section{EXPERIMIENT 2}

\section{Method}

Twenty psychology students participated to fulfill a course requirement. One to three subjects were tested at a time. The target items were 102 randomly chosen words from a set of eight-letter target words reported by Peynircioğlu and Watkins (1986). Two of the words served as practice items; the remaining 100 words were randomly assigned to two 50-word lists. One of the 50-word lists was randomly designated the study list, and the other was used to construct the fragments for the word-fragment-completion test. The study list was typed on a sheet of paper, double spaced in capital letters. Unlike in Experiment 1, the list of $\mathbf{5 0}$ words that the subjects studied were not the words that they were tested on during the word-fragment-completion test. In essence, this experiment had two nonstudy groups, one informed and the other deceived. For the testing phase, the unique two-letter fragments designated by Peynircioglu and Watkins were used to make the cues for the word-fragmentcompletion test. In this experiment, the first letter of a word was used to construct its unique two-letter fragment. Additional letters were randomly added on to the two-letter fragments to make the three-, four-, and five-letter fragments in the incremental condition. Only the fiveletter fragment cue was used in the standard condition. The answer sheets for this experiment were identical in design to those used in Experiment 1 .

The procedure followed in this experiment is similar to that in Experiment 1 . All subjects heard detailed instructions and were presented with the two practice items. The subjects in the study condition then read the list of $\mathbf{5 0}$ words silently to themselves at a rate of one word per $2 \mathrm{sec}$, as timed by the experimenter, and then were given the word- fragment-completion test. The subjects in the nonstudy condition were given the word-fragment-completion test. The test was composed of 25 words cued in the standard condition and 25 in the incremental condition. Across subjects, words occurred equally often in the standard and incremental test formats. Presentation condition (deceived or nonstudy) was a between-subject factor, and test format (standard or incremental) was a within-subject factor.

\section{Results}

The subjects in the deceived group completed $54 \%$ of the words cued in the standard condition and $46 \%$ of the words cued in the incremental condition. The subjects in the nonstudy condition completed $59 \%$ of the words cued in the standard condition and $50 \%$ of the words cued in the incremental condition. An ANOVA established that the effect of group $\left[F(1,18)=1.37, M S_{\mathrm{e}}=10.51\right]$ was not significant. The effect of test format $[F(1,18)=$ $\left.13.27, M S_{\mathrm{e}}=3.32\right]$ was significant. The interaction between group and test format $\left[F(1,18)=0.03, M S_{\mathrm{e}}=\right.$ 3.32] was not significant.

\section{DISCUSSION}

This study further investigated the cue-depreciation effect and attempted to induce the effect in words that had not been previously primed. In Experiment 1, the first letter of each item cued in the incremental condition was not revealed until the last fragment. In this experiment, both study and nonstudy groups completed a significantly higher percentage of words cued in the standard condition than in the incremental condition. Similar results were found in Experiment 2. A significantly higher percentage of words cued in the standard condition was completed compared with the incremental condition in both the deceived and nonstudy groups.

The two studies reported here present evidence that supports the hypothesis that the cue-depreciation effect does not result entirely from priming alone; rather, it can be demonstrated on unprimed words as well. The circumstances that are required for the cue-depreciation effect to be found on unprimed words are, unfortunately, still unclear. However, other evidence suggests that even subtle changes in the strategies employed by subjects might play an important role (see Thapar \& Greene, 1992).

\section{REFERENCES}

Gibson, J. M., \& WATKINS, M. J. (1988). A pool of 1,086 words with unique two-letter fragments. Behavior Research Methods, Instruments, \& Computers, 20, 390-397.

Peynircioğlu, Z. F., \& Watkıns, M. J. (1986). Cue depreciation: When word fragment completion is undermined by prior exposure to lesser fragments. Journal of Experimental Psychology: Learning, Memory, \& Cognition, 12, 426-431.

ThAPAR, A., \&REene, R. L. (1992). A strategic account of the cuedepreciation effect. Manuscript submitted for publication.

(Manuscript received March 9, 1992.) 